are scarce [4-6]. Andropoulos, et al. [4] used external anatomical landmarks or transesophageal echocardiography (TEE) to guide CVC placement in 456 children undergoing surgery for congenital heart disease (CHD) and checked the placement on the first postoperative chest $X$-ray. With this data, formulae for the correct insertion length for right-sided internal jugular vein (IJV) and subclavian vein (SCV) catheters were made based on the patient's height. The formulae predicted the correct catheter length, i.e., position above the RA, in 97\%. Andropoulos' formulae found wide acceptance and are widely used. In a study on 60 preoperative infants and children by Yoon, et al. [5], right IJV catheters were positioned using TEE. They formulated a guideline to correctly position a right IJV catheter in $97.5 \%$ patients with an accuracy of $95 \%$, in children with height between 40 and $140 \mathrm{~cm}$. Similarly, in 90 children $<5$ years age, $\mathrm{Na}$, et al. [6] placed right IJV catheters using the sternal head of the clavicle and the nipples as external landmarks to determine the position of the carina. This method required no formula or any preoperative chest $X$-ray, or any other sophisticated methods like TEE or electrocardiographic guidance.

In contrast to the above studies, Witthayapraphakorn, et al. [1] have measured the actual distance from the point of insertion of a right IJV catheter to the position in the SVC to be correctly located above the RA, on computerised tomography (CT) images of 165 children. They measured the distance from the presumed skin puncture site to the SVC at the level of the carina and the RA-SVC junction. Inter-and intra-observer agreement was good and the study was adequately powered. With the data thus obtained, using regression analysis, a formula was devised to calculate the depth of the right IJV catheter based on the age in months and body surface area. Finally, for ease of recall, simple recommendations for length of catheter insertion have been made for different ages (not using the complicated formula) starting at $6.5 \mathrm{~cm}$ at 1 year of age and increasing by 0.5 $\mathrm{cm}$ till 12 years of age, $13 \mathrm{~cm}$ at 13 years and remaining at $14 \mathrm{~cm}$ beyond this age.

Unfortunately, the study gives no information for CVC placements for the left IJV/SCV or right SCV catheters. The number of children $<1$ yr age was only 8 and hence, the values do not represent an adequate sample. Perhaps, keeping this in mind, the authors' recommendations start from the age of one year. External validation of the recommendations is awaited.

Funding: None; Competing interests: None stated.

\section{REFERENCES}

1. Witthayapraphakorn L, Khositseth A, Jiraviwatana T, Siripornpitak S, Pornkul R, Anantasit N, et al. Appropriate length and position of the central venous catheter insertion via right internal jugular vein in children. Indian Pediatr. 2013; 50:749-52.

2. Vesely TM. Central venous catheter tip position: a continuing controversy. J Vasc Interv Radiol. 2003;14:527-34.

3. Albrecht K, Breitmeier D, Panning B, Tröger HD, Nave $\mathrm{H}$. The carina as a landmark for central venous catheter placement in small children. Eur J Pediatr. 2006;165: 264-6.

4. Andropoulos DB, Bent ST, Skjonsby B, Stayer SA. The optimal length of insertion of central venous catheters for pediatric patients. Anesth Analg. 2001;93:883-6.

5. Yoon SZ, Shin TJ, Kim HS, Lee J, Kim CS, Kim SD, et al. Depth of a central venous catheter tip: length of insertion guideline for pediatric patients. Acta Anaesthesiol Scand. 2006;50:355-7.

6. Na HS, Kim JT, Kim HS, Bahk JH, Kim CS, Kim HD. Practical anatomic landmarks for determining the insertion depth of central venous catheter in paediatric patients. Br J Anaesth. 2009;102:820-3.

\title{
Anticonvulsants for Neonates: High Time We Were Seized of the Matter
}

\author{
SOURABh DUtTa \\ Division of Neonatology, Department of Pediatrics, PGIMER, Sector 12, Chandigarh 160 023, India. \\ sourabhdutta@yahoo.co.in
}

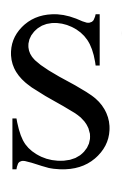

eizures are a common problem in the neonatal intensive care unit (NICU). Surprisingly, there is scant evidence regarding the optimal anticonvulsant for treating neonatal seizures [1]. In the USA, of the neonatal seizures that are treated with a non-benzodiazepine drug, phenobarbitone accounts for $76 \%$ and phenytoin for $16 \%$ [2]. Until now, the only good quality randomised controlled trial (RCT) comparing phenobarbitone and phenytoin was by Painter, et al. [3] in 1999. Pathak, et al. [4] have conducted a much-needed 
randomized controlled trial comparing phenobarbitone and phenytoin. This RCT is commendable because it was conducted within the resource constraints of a level II neonatal unit in India. They were unable to measure serum phenobarbitone and phenytoin levels, presumably owing to financial constraints. The authors also acknowledge that their unit-like most units in developing countries has no access to EEG monitoring.

However, the fact remains that the non-availability of EEG raises several methodological issues. The correct clinical identification rate of clonic seizures is only $66 \%$; of subtle seizures is $32 \%$ and of non-seizure movements is $47 \%$ [5]. The inter-observer agreement (kappa) among pediatricians for the identification of neonatal seizures is just 0.21 . Thus, in clinical practice, there is widespread overdiagnosis and underdiagnosis of neonatal seizures and disagreement between observers [6]. This poses a problem in a research study, such as the one conducted by Pathak, et al. [4], where the inclusion of patients is solely on clinical grounds. The relationship between EEG and clinical seizures is particularly weak in the case of subtle seizures and tonic seizures; and in the current study, $87 \%$ of all seizures were either subtle or tonic [4,7]. In this open-label trial with fixed, small block sizes (27 blocks of 4 each), non-concealment of allocation towards the end of each block was inevitable. Thus, at least 27 (25\%) patients would have their allocated intervention known beforehand. A selection bias in allocating $25 \%$ or more patients could easily swing the results of the study. Being open-label, there was an unavoidable risk of performance and ascertainment bias - further compounded by the fact that cessation of neonatal seizures (like the diagnosis of seizures) has a high rate of misclassification and interobserver disagreement. Pathak, et al. [4] did not mention the time frame for measurement of the primary outcome nor the waiting time before giving the second anticonvulsant for persistent seizures- both of which could affect the measurement of the primary outcome.

Painter, et al. [3] had enrolled neonates on the basis of a risk for seizures and presence of electrographic evidence of seizures. They reported no evidence of the superiority of phenobarbitone or phenytoin in terms of electrographic seizure cessation. The small sample size precluded any change of practice based on Painter's study alone. Pathak, et al. [4] claim a much higher success rate for phenobarbitone for clinical seizures and recommend its use. Previous EEG-based studies-both randomized and non-randomized - on the efficacy of phenobarbitone have reported efficacy rates ranging from $43 \%$ to $50 \%$ only $[3,8,9]$; hence the efficacy rate of $72 \%$ in the study by Pathak, et al. [4] is exceptional. They state that their study resembles real-life situations in developing countries and therefore has a high external validity. However, one must be cautious before accepting this conclusion because without robust internal validity, external validity is of limited relevance.

There is an urgent need for large, well-designed RCTs with a low-risk of bias and adequate follow-up, comparing phenobarbitone with phenytoin and newer anti-convulsants. The RCT by Pathak, et al. [4] has certainly brought back our focus on to this important area. It is high time that researchers in this field were seized of the matter.

Funding: None; Competing interests: None declared.

\section{REFERENCES}

1. Booth D, Evans DJ. Anticonvulsants for neonates with seizures. Cochrane Database Syst Rev. 2004;CD004218.

2. Blume HK, Garrison MM, Christakis DA. Neonatal seizures: treatment and treatment variability in 31 United States pediatric hospitals. J Child Neurol. 2009;24:14854.

3. Painter MJ, Scher MS, Stein AD, Armatti S, Wang Z, Gardiner JC, et al. Phenobarbital compared with phenytoin for the treatment of neonatal seizures. N Engl J Med. 1999;341:485-9.

4. Pathak G, Upadhyay A, Pathak U, Chawla D, Goel SP. Phenobarbitone and phenytoin for treatment of neonatal seizures: Open-label randomized controlled trial. Indian Pediatr. 2013;50:753-7.

5. Malone A, Ryan CA, Fitzgerald A, Burgoyne L, Connolly $\mathrm{S}$, Boylan GB. Interobserver agreement in neonatal seizure identification. Epilepsia. 2009;50:2097-101.

6. Scher MS, Aso K, Beggarly ME, Hamid MY, Steppe DA, Painter MJ. Electrographic seizures in preterm and fullterm neonates: clinical correlates, associated brain lesions, and risk for neurologic sequelae. Pediatrics. 1993;91:128-34.

7. Mizrahi EM, Kellaway P. Characterization and classification of neonatal seizures. Neurology. 1987;37:1837-44.

8. Boylan GB, Rennie JM, Chorley G, Pressler RM, Fox GF, Farrer $\mathrm{K}$, et al. Second-line anticonvulsant treatment of neonatal seizures: a video-EEG monitoring study. Neurology. 2004;62:486-8.

9. Castro Conde JR, Hernandez Borges AA, Domenech ME, Gonzalez CC, Perera SR. Midazolam in neonatal seizures with no response to phenobarbital. Neurology. 2005;64:876-9. 